\title{
VARIÁVEL-RESPOSTA NO CÓRREGO DO CEDRO, PRESIDENTE PRUDENTE-SP
}

\author{
Carolina Sayuri Matsumoto ${ }^{1}$ \\ Renata Ribeiro de Araújo ${ }^{2}$ \\ Mariana Bardella Thomaz ${ }^{3}$ \\ Gabriel Chain Pinto Portas ${ }^{4}$
}

RESUMO: O presente trabalho teve como objetivo desenvolver um modelo quantitativo para a predição da concentração de oxigênio dissolvido na água do Córrego do Cedro, Presidente Prudente-SP. Para tanto, foram realizadas campanhas de campo para amostragens de variáveis ambientais e de alíquotas de água para análise laboratorial de variáveis limnológicas. Posteriormente foi realizado tratamento estatístico dos dados, gerando-se um modelo o qual correlacionou variáveis amostradas à variável-resposta oxigênio dissolvido. Este trabalho mostrou ser possível predizer uma variável importante partindo de variáveis que expressam fatores-chave e ressaltou a importância da continuidade de um monitoramento ambiental para a melhoria da eficiência de modelos preditivos para ambientes aquáticos, em especial, o Córrego do Cedro.

Palavras chave: Córrego do Cedro. Oxigênio dissolvido. Variável-resposta.

\section{Introdução}

Em países como o Brasil, onde os problemas de poluição aquática e a necessidade de ferramentas que auxiliem a identificar os problemas crescem rapidamente, a capacidade de predição tem grande importância. Para tanto, necessita-se de variáveis com baixo custo de aquisição que possam predizer 
outras variáveis importantes na quantificação da magnitude do impacto, que apresentam, de maneira geral, um custo mais elevado (Thomaz \& Bini, 1999).

Frequentemente, variáveis importantes para a descrição de um processo ecológico são difíceis de serem determinadas. Em compensação, algumas variáveis podem ser controláveis e/ou facilmente mensuráveis.

As técnicas de Análise de Regressão permitem estabelecer uma representação matemática dessa relação a partir de um conjunto de dados. $\mathrm{A}$ partir desse modelo matemático, é possível prever a resposta de uma variável em função de outras, traçando, desta forma, uma possível tendência e/ou padrão em seu comportamento.

Especificamente tratando-se dos ecossistemas aquáticos, a limnologia preditiva fornece modelos quantitativos que permitem um manejo adequado de seus recursos hídricos. Tais modelos têm larga aplicação nestes ecossistemas, sendo aplicados no controle de eutrofização, a partir da predição do impacto de nutrientes; no monitoramento da biota aquática, através da predição de sua produção e no estudo de possíveis padrões e tendências espaciais e temporais do ambiente, por meio da predição de variáveis bióticas e abióticas.

Segundo Souza (2004), isso possibilita estimar a influência causada pela ocupação humana, por atividades econômicas e pelos usos da água na bacia, fornecendo subsídios para o gerenciamento adequado dos recursos hídricos.

A predição do oxigênio dissolvido torna-se relevante uma vez que suas concentrações são indicativas de produção/respiração em ecossistemas aquáticos. As principais fontes de oxigênio para a água são a atmosfera e a fotossíntese. Por outro lado, as perdas ocorrem através do consumo pela decomposição de matéria orgânica (oxidação), transferências para a atmosfera, respiração de organismos aquáticos e oxidação de íons metálicos, como por exemplo, o ferro e o manganês (Wetzel, 1983; Esteves, 1998). Sendo assim, as variáveis associadas aos processos de produção e consumo de oxigênio, tem grande influencia sobre as concentrações de oxigênio dissolvido em ambientes aquáticos. 


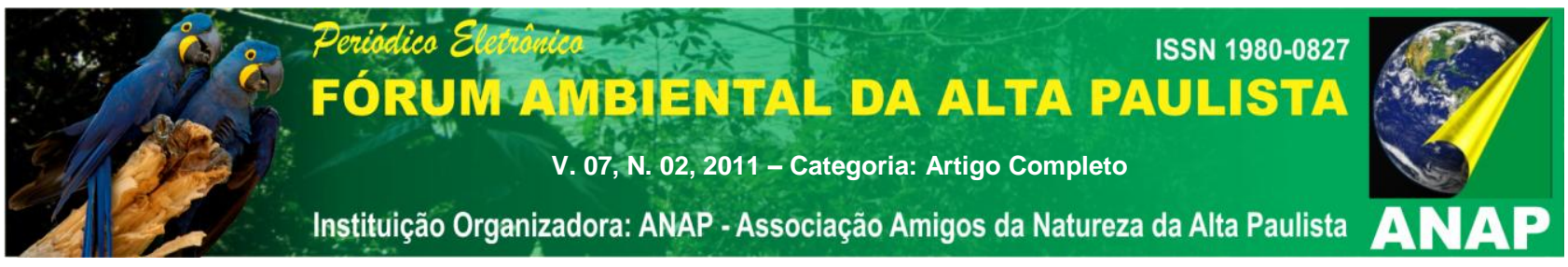

Assim, o presente trabalho teve como objetivo desenvolver um modelo preditivo para a concentração de oxigênio dissolvido na água do Córrego do Cedro, Presidente Prudente - SP.

\section{Desenvolvimento}

\section{1 Área de Estudo}

O Córrego do Cedro está localizado ao sul do perímetro urbano do município de Presidente Prudente - SP estendendo-se por aproximadamente 12,3 quilômetros e abrangendo uma área de $40,96 \mathrm{~km}^{2}$. Ele pertence à Unidade de Gerenciamento de Recursos Hídricos 22 - Pontal do Paranapanema. Ele é um dos principais afluentes do manancial do Rio Santo Anastácio. Atualmente, o rio Santo Anastácio supre cerca de $30 \%$ das necessidades de abastecimento público do município, desta forma, ressalta-se a importância do Córrego do Cedro.

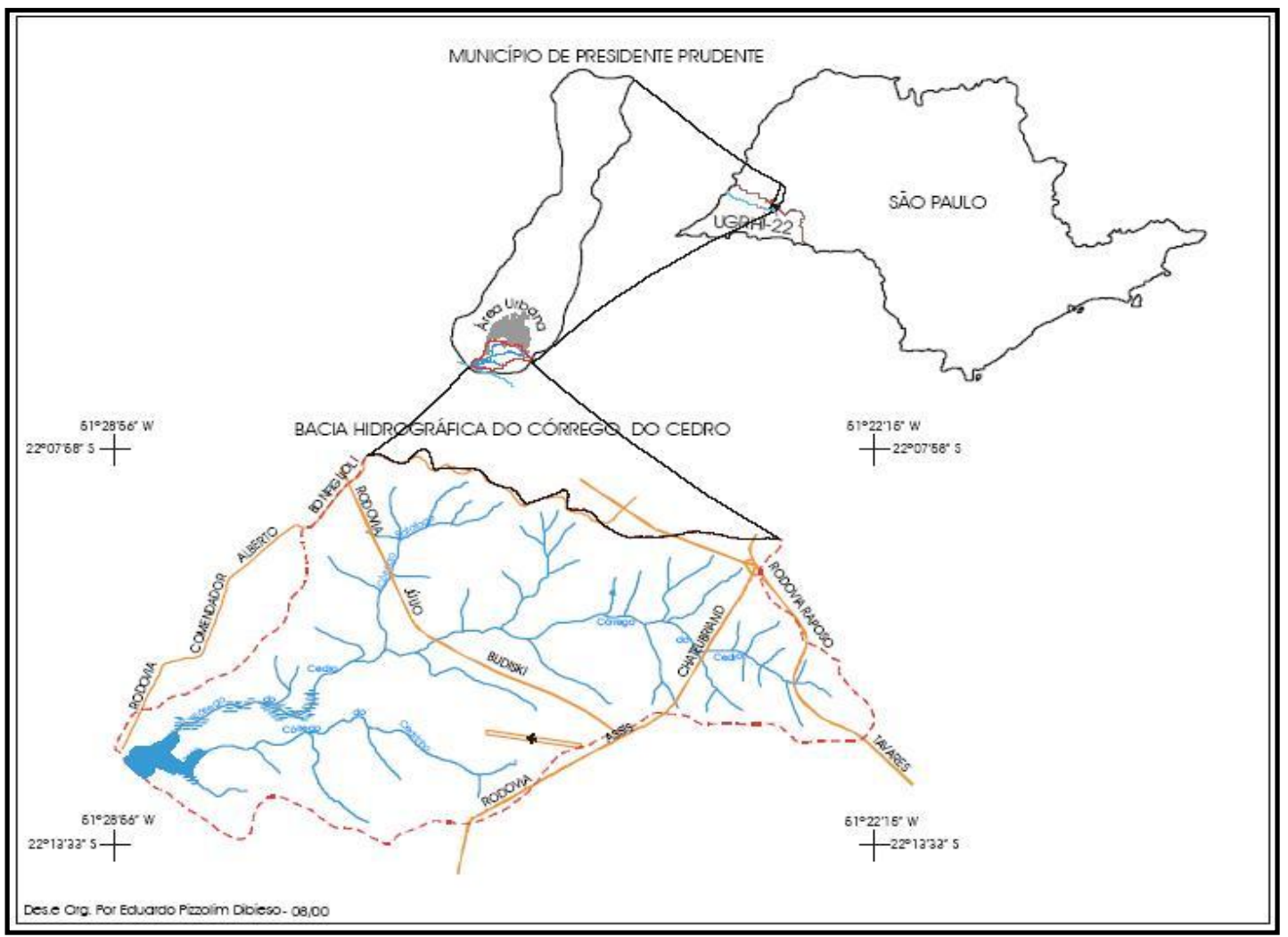




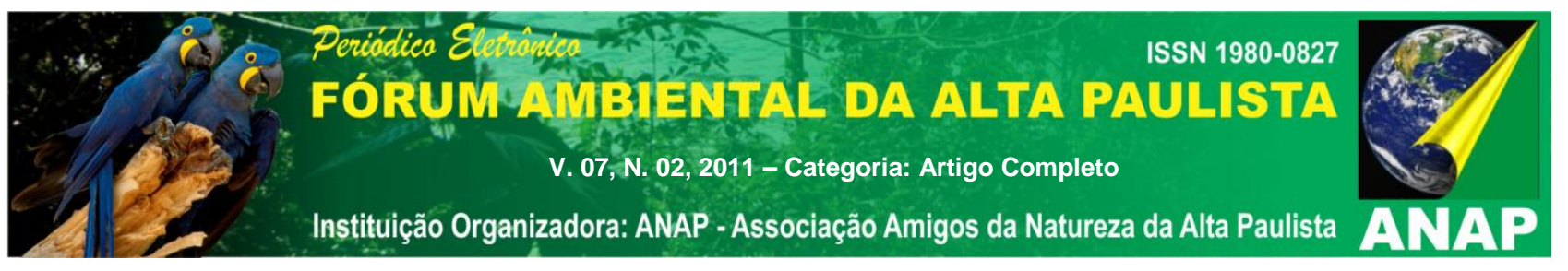

Figura. 01. Localização da Bacia do Córrego do Cedro. (fonte: ARROIO JUNIOR, 2010)

Pelo Decreto Estadual ํo 10.755 de 22 de novembro de 1977 o córrego é enquadrado como Classe II.

No presente trabalho, foram escolhidas sete estações de amostragem ao longo do curso d'água (fig. 02) tendo como critério de escolha, as atividades no

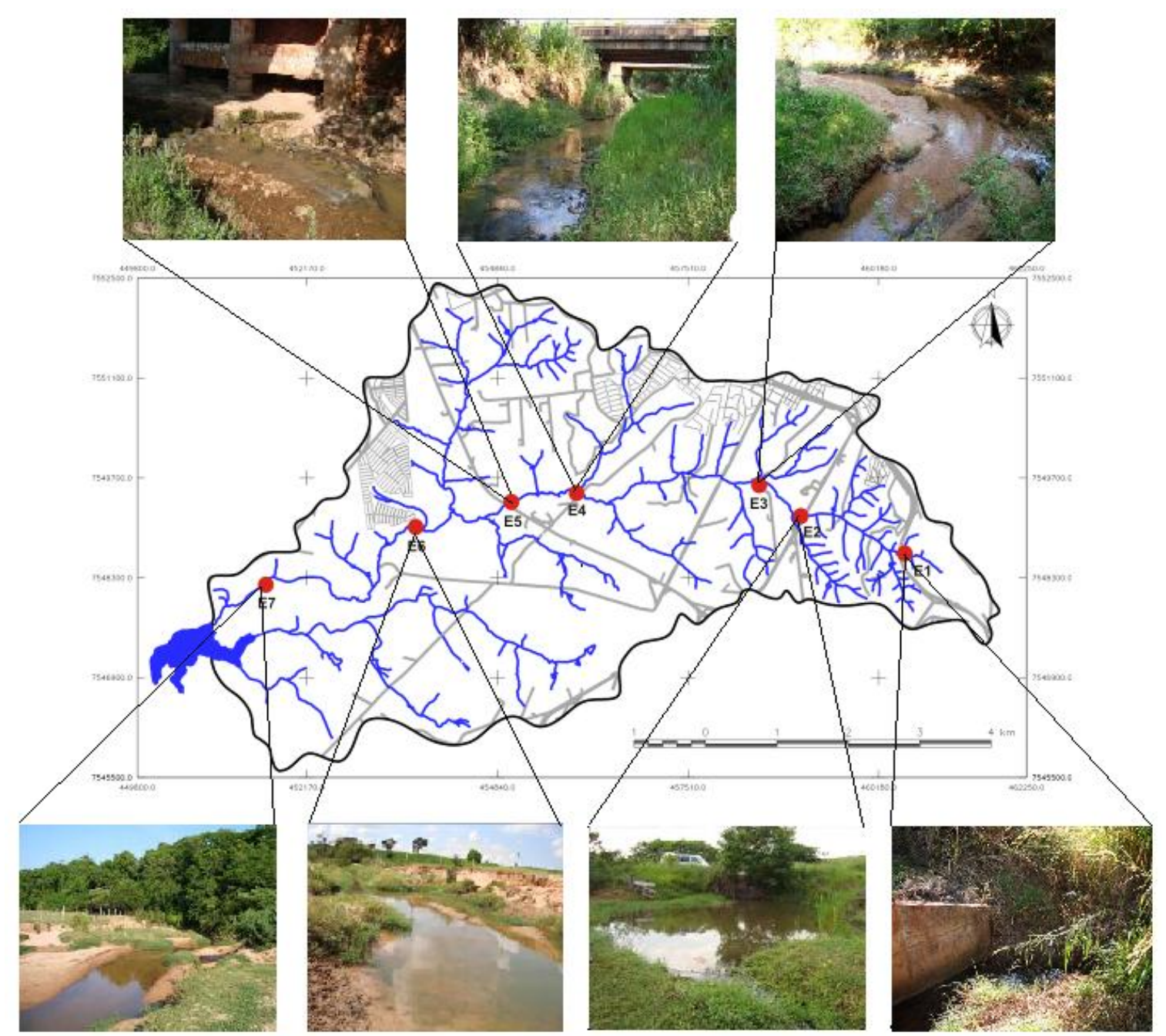

entorno que pudessem refletir no comportamento do Córrego.

Figura 02. Localização das estações de amostragem no Córrego do Cedro 


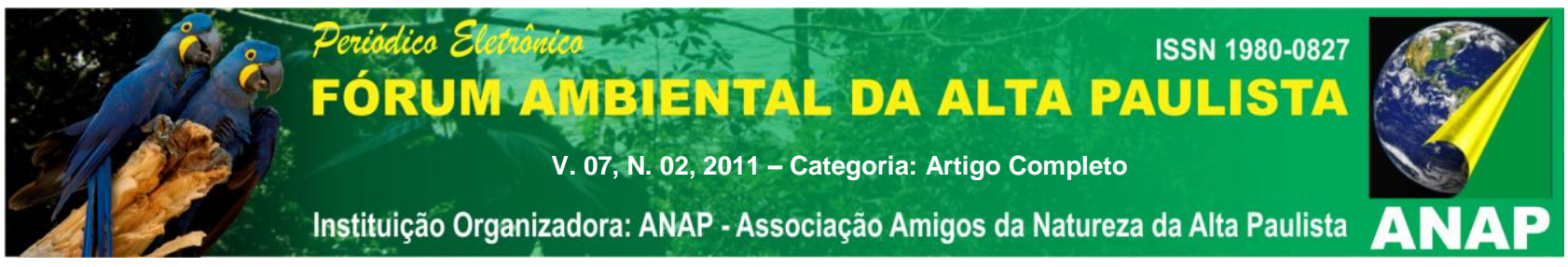

O quadro 01 localiza cada um desses pontos, fornecendo suas coordenadas geográficas e um referencial.

Quadro 01. Pontos de referência e coordenadas das sete estações de amostragem no córrego

\begin{tabular}{cc}
\hline Estação & Coordenadas (UTM) \\
\hline 1 & $\mathrm{E}=460.512 \mathrm{~m}$ \\
& $\mathrm{E}=7.548 .642 \mathrm{~m}$ \\
2 & $\mathrm{~N}=759.076 \mathrm{~m}$ \\
& $\mathrm{E}=458.501 \mathrm{~m}$ \\
3 & $\mathrm{~N}=7.549 .634 \mathrm{~m}$ \\
& $\mathrm{E}=455.999 \mathrm{~m}$ \\
4 & $\mathrm{~N}=7.549 .519 \mathrm{~m}$ \\
& $E=454.940 \mathrm{~m}$ \\
5 & $N=7.549 .310 \mathrm{~m}$ \\
6 & $E=453.729 \mathrm{~m}$ \\
7 & $N=7.549 .010 \mathrm{~m}$ \\
& $E=451.663 \mathrm{~m}$ \\
& $N=7.548 .285 \mathrm{~m}$ \\
\hline
\end{tabular}

\subsection{Metodologia}

Primeiramente, foi realizado o levantamento de dados através de campanhas de coletas em sete estações de amostragem ao longo do Córrego do Cedro, da nascente à foz. Ao todo, 25 variáveis limnológicas foram analisadas. In loco foram mensurados o pH, o oxigênio dissolvido, a turbidez, a condutividade elétrica e a temperatura por meio dos aparelhos digitais portáteis pHmetro Instrutherm modelo pH-1400, oxímetro Instrutherm modelo MO-890, turbidímetro PoliControl AP 2000, condutivímetro Instrutherm CD-830 e termômetro do pHmetro, respectivamente.

Para posterior análise em laboratório foram coletadas alíquotas de água, para a determinação da série de sólidos, clorofila- $a$, fósforo total, fósforo total 
dissolvido, ortofosfato, nitrito, nitrato, nitrogênio kjeldhal e dureza. As amostras foram acondicionadas em recipientes de polietileno e dentro de uma caixa de material isolante com gelo a fim de mantê-las refrigeradas.

Em laboratório, as amostras foram filtradas em membranas de fibra de vidro de $24 \mathrm{~mm}$, utilizando o sistema bomba a vácuo, e armazenadas no congelador para posterior determinação das formas dissolvidas de nutrientes: fósforo dissolvido, fósforo reativo solúvel, nitrito e nitrato.

A série de sólidos foi determinada por método gravimétrico, conforme APHA (1995). Evaporando uma pequena alíquota de amostra colocada em cápsula e levada a estufa a $105^{\circ} \mathrm{C}$ por 24 horas, seguida da pesagem do material residual, determinou-se os sólidos totais. Os sólidos suspensos foram determinados filtrando amostras em membranas de vibra de vidro $24 \mathrm{~mm}$ e evaporando dos filtros em estufa a $105^{\circ} \mathrm{C}$, seguida de pesagem. $\mathrm{Na}$ determinação das porções fixas e voláteis, os materiais residuais, tanto na cápsula quanto na membrana, foram calcinados em mufla a $550^{\circ} \mathrm{C}$ durante 30 minutos, seguindo para pesagem, obtendo-se os sólidos totais fixos e voláteis e os sólidos suspensos fixos e voláteis. A partir das formas de sólidos encontradas anteriormente foram determinados os sólidos dissolvidos, sólidos dissolvidos fixos e sólidos dissolvidos voláteis.

Para a determinação de clorofila a foi realizada filtragem em membrana de vidro, seguida de congelamento do material em ambiente escuro. A extração da clorofila a se deu através de maceração do filtro com acetona $90 \%$ a frio, seguida de centrifugação a $2500 \mathrm{rpm}$ e leituras a $663 \mathrm{~nm}$ e $750 \mathrm{~nm}$ em espectrofotômetro, conforme Golterman et al. (1978).

O fósforo total, fósforo dissolvido e ortofosfato foram determinados segundo metodologia de Mackereth et al. (1978). As frações de fósforo total e de fósforo dissolvido foram quantificadas após a digestão com persulfato de potássio em autoclave e posterior reação com adição de reagente misto, formado por molibdato de amônia, tartarato de antimônio e potássio e ácido ascórbico, seguida de leitura em espectrofotômetro a $882 \mathrm{~nm}$. A diferença entre 
a determinação do fósforo total e do fósforo dissolvido é que neste utilizou-se a amostra filtrada e no outro, amostra não filtrada. Já o ortofosfato foi obtido diretamente após reação com reagente misto, sem necessidade de digestão, com posterior leitura em espectrofotômetro a $882 \mathrm{~nm}$.

A determinação do nitrato foi realizada através de leitura direta da amostra filtrada em espectrofotômetro a $220 \mathrm{~nm}$ e $275 \mathrm{~nm}$. O nitrito foi determinado utilizando-se a amostra filtrada, através do método da sulfanilamida, através da formação de um composto de coloração púrpura em $\mathrm{pH}$ baixo, pela diazotação do ácido sulfanílico com o dicloreto de $\mathrm{N}$-(1-naftil)etilenodiamino de acordo com APHA (1995). A leitura foi realizada em espectrofotômetro a $543 \mathrm{~nm}$. Tanto para o nitrato quanto para o nitrito foi necessário desenvolver a curva de calibração.

Determinou-se o nitrogênio Kjeldahl total pelo método de Kjeldahl, segundo procedimentos do Inst. Adolfo Lutz (1985). Inicialmente foi realizado um procedimento de concentração das amostras não filtradas através da evaporação em chapa. Em seguida, o material foi aquecido em bloco digestor com ácido sulfúrico e sulfato de potássio, de maneira a converter as formas nitrogenadas orgânicas e amônia livre em sulfato de amônia. Feito isso, ocorreu a destilação da amônia na presença de hidróxido de sódio, a qual foi absorvida em uma solução de ácido bórico. Por fim, a solução foi titulada com ácido sulfúrico.

A soma dos valores de nitrogênio Kjeldahl total, nitrito e nitrato, descritas anteriormente, resulta no nitrogênio total.

A dureza total das amostras foi determinada por meio de Kit colorimétrico, cujo princípio baseia-se no método titulométrico do EDTA que consiste na viragem de cor pela complexação de todo cálcio e magnésio da solução

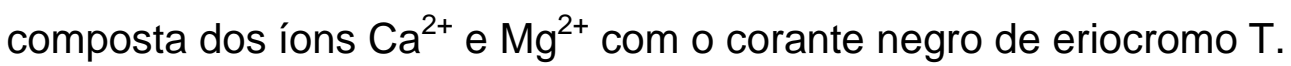

Para a determinação da DBO foi realizado um teste padrão, mantendo a amostra incubada a uma temperatura constante de $20^{\circ} \mathrm{C}$ durante de 5 dias, de acordo com APHA (1995). 


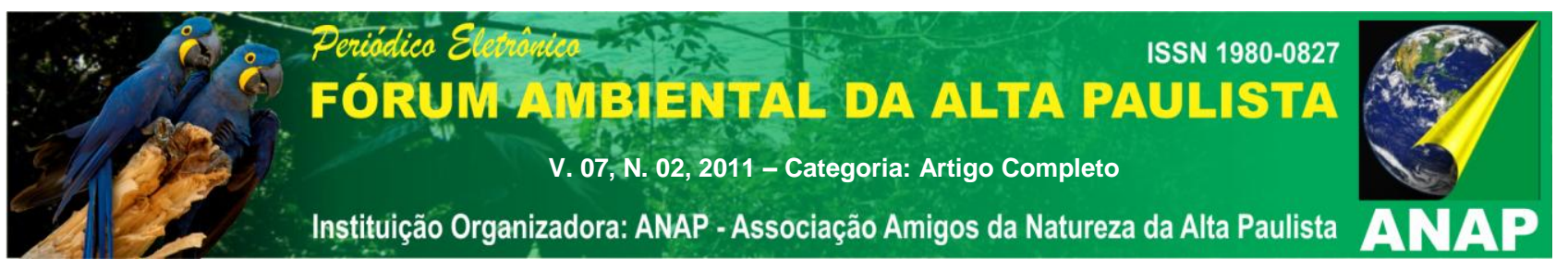

Os resultados foram armazenados em um banco de dados utilizando-se software Excel ${ }^{\circledR}$ organizado por pontos de amostragem e data de coleta. Posteriormente, os dados foram logaritmizados em base 10 para reduzir as discrepâncias entre os valores. Em seguida, foi criada uma tabela com esses valores logaritmizados no software Statistica ${ }^{\circledR}$, onde foi realizada a análise de regressão múltipla, gerando a equação preditiva de oxigênio dissolvido na água do Córrego do Cedro. O software também permitiu observar a correlação entre as variáveis. 


\subsection{Resultado e Análise}

Após realizar a regressão múltipla foi gerado um modelo o qual reteve a temperatura (T), o pH, a dureza (Dur) e a vazão (Q) como variáveis independentes. Este modelo preditivo para a concentração de oxigênio dissolvido está apresentado na equação (1).

$$
\begin{aligned}
& \log (O D)=-0,0080+0,2759 \log (T)+0,5321 p H-0,0236 \log (d u r) \\
&+2,8901 \log (Q) \\
&\left(n=264 ; R^{2}=0,7031 ; \mathrm{F}(4,259)=153,36 ; p<0,000\right)
\end{aligned}
$$

Estatisticamente, a relação entre a variável dependente e as variáveis independentes foi satisfatória, o que pode ser notado pelo valor do $R^{2}$ o qual mostra que o modelo explica $70,31 \%$ da variabilidade dos dados.

O modelo matemático proposto apresentou proporcionalidade positiva entre as variáveis temperatura, $\mathrm{pH}$ e vazão. Esta relação entre a temperatura e o oxigênio dissolvido pode ser explicada pelo fato de que com o aumento da temperatura pode haver o aumento do metabolismo dos autótrofos e, por conseguinte o incremento de oxigênio via produção fitoplanctônica.

A proporcionalidade positiva em relação ao $\mathrm{pH}$ pode estar relacionada ao fato de que durante a remoção do dióxido de carbono, ocorrida no processo de fotossíntese, produção de oxigênio dissolvido, os valores de $\mathrm{pH}$ se elevam consideravelmente.

Já a relação positiva encontrada para a vazão pode ser interpretada como sendo devido ao maior turbilhonamento da água. Essa movimentação e fluxo contínuo do córrego favorecem sua aeração, ou seja, a incorporação do oxigênio na água por difusão. 
Tabela 02. Sumário do modelo da regressão múltipla (usando para seleção das variáveis 0 procedimento Forward-stepwise) entre a variável dependente oxigênio dissolvido e as variáveis independentes temperatura, dureza, pH e vazão.

\begin{tabular}{lccc}
\hline $\begin{array}{l}\text { Variável } \\
\text { independente }\end{array}$ & B & $\boldsymbol{t}(\mathbf{2 5 9 )}$ & $\boldsymbol{p}$-level \\
\hline Log T & 0,275946 & 4,20788 & 0,000036 \\
Log dur & $-0,023570$ & $-1,92491$ & 0,055335 \\
pH & 0,532079 & 5,16362 & 0,000000 \\
Log Q & 2,890104 & 3,16437 & 0,001740 \\
\hline
\end{tabular}

\section{Conclusão}

Estudos como este tem grande relevância para a interpretação da dinâmica do Córrego e para o fomento de ações que visem à conservação deste ecossistema, essencial ao abastecimento público de água.

O presente trabalho demonstrou que é possível predizer elementos importantes na dinâmica e na caracterização de ecossistemas aquáticos, como o oxigênio dissolvido, utilizando variáveis como temperatura, turbidez, $\mathrm{pH}$ e vazão. O modelo gerado foi satisfatório no que diz respeito à quantidade de variáveis independentes retida, pois são de rápida e fácil obtenção, já que são obtidas pela medição direta por meio de aparelhos digitais portáteis ou são conseguidas por simples medição e posterior cálculo algébrico.

Porém, vale comentar que, apesar de ter explicado 70,31\% da variabilidade dos dados, o modelo poderia ser melhorado para que seja mais representativo. Isso ressalta a importância da continuidade do monitoramento ambiental no Córrego do Cedro para o aperfeiçoamento desta modelagem e a validação do modelo matemático gerado.

\section{Referências}




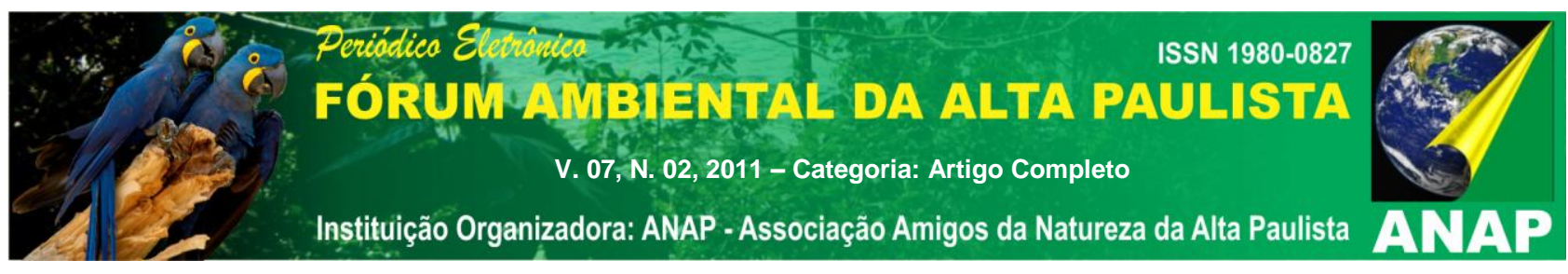

ARROIO JUNIOR, P. P. Análise ambiental da bacia hidrográfica do córrego do cedro, município de presidente prudente-sp: monitoramento limnológico e técnicas de geoprocessamento. 2010. Trabalho de conclusão de curso (graduação em Engenharia Ambiental). Faculdade de Ciência e Tecnologia, Universidade Estadual Paulista, São Paulo.

DIBIESO, E. P. Planejamento ambiental da bacia hidrográfica do córrego do Cedro Presidente Prudente/SP. Presidente Prudente, 2007. Dissertação (Mestrado em Geografia) Faculdade de Ciências e Tecnologia, Universidade Estadual Paulista, São Paulo.

KASZNAR, I. K.; GOLÇAVES, B. M. L. Regressão múltipla: uma digressão sobre seus usos. Disponível em: < http://www.ibci.com.br/Regressao_Multipla.pdf> Acesso em: 01 ago 2011

Resolução CONAMA 357 de 17 de março de 2005 . Disponíel em: <http://www.mma.gov.br/port/conama/res/res05/res35705.pdf> Acesso em: 02 ago. 2011

ROCHA, R. R. A. Limnologia Comparativa e Preditiva de Rios e Lagoas da Planície de Inundação do Alto Rio Paraná (PR/MS - Brasil). 2003. Tese (doutorado em Ciências Ambientais). Centro de Ciências Biológicas, Universidade Estadual de Maringá, Paraná.

SOUZA, J. D. de. Modelo espaço - temporal em SIG para análise de qualidade da água em uma Bacia Hidrográfica. Curitiba, 2004. Dissertação (Mestrado em Ciências Geodésicas) Universidade Federal do Paraná, Paraná.

WETZEL, R. G. Limnology. Saunders College Publishing,1983. 767p. 